\title{
A Pesquisa INTERVENÇÃo COMO EXERCíCIO ÉTICO E A METODOLOGIA COMO PARASKEUÉ
}

Jéssica Prudente, Jaqueline Tittoni ${ }^{\star}$

Universidade Federal do Rio Grande do Sul, Porto Alegre, RS, Brasil

\section{Resumo}

A partir da leitura dos estudos de Michel Foucault sobre a ascese como exercício ético e a paraskeué como equipamento deste exercício, traçamos possíveis relações destes elementos teóricos com as estratégias metodológicas propostas pela pesquisa intervenção e pela intervenção fotográfica. A reflexão teórica deste estudo sugere que tais estratégias são condições de possibilidade para que o processo da pesquisa se constitua como um exercício ético. As referências teóricas estão baseadas no livro "A Hermenêutica do Sujeito" de Michel Foucault e em artigos sobre a pesquisa intervenção e a intervenção fotográfica, indicando esta metodologia como um "equipamento" da ascese na pesquisa.

Palavras-chave: pesquisa intervenção; intervenção fotográfica; ascese; paraskeué.

\section{THE INTERVENTION RESEARCH AS AN ETHICAL EXERCISE AND THE METHODOLOGY AS AN PARASKEUÉ}

\begin{abstract}
Based on the Michel Foucault's studies about the ascesis as an ethical exercise and the paraskeue as an instrument of this exercise, the possible relations of these theoretical elements with the methodological strategies proposed by the research's intervention and the photographic intervention were traced. The theoretical thinking of this study suggests that these strategies are possibility conditions for the research's process be constituted as an ethical exercise. The theoretical references are based on the book "The Hermeneutics of the Subject" by Michel Foucault and articles about the intervention research and photographic intervention, designating this methodology as an "instrument" of the research's ascesis.
\end{abstract}

Keywords: Intervention Research; Photographic Intervention; Ascesis; Paraskeué.

\footnotetext{
^Endereço para correspondência: Universidade Federal do Rio Grande do Sul, Instituto de Psciologia. Ramiro Barcelos, 2600 - sala 201. Santana. 90100-550 - Porto Alegre, RS - Brasil. E-mail: jessiprud@gmail.com, jaquemin@terra.com.br
} 
Este artigo é um desdobramento da dissertação de mestrado intitulada "Tempo, trabalho e fotografia: a produção de práticas reflexivas nos jogos de verdade do trabalho em saúde", apresentada no Programa de Pós-Graduação em Psicologia Social e Institucional da Universidade Federal do Rio Grande do Sul. Nesta discussão, enfatizamos o objetivo de problematizar a pesquisa intervenção como um exercício ético e a metodologia como uma paraskeué, utilizando, como referência, as discussões propostas por Michel Foucault na obra "A Hermenêutica do Sujeito". Ainda, apresenta a intervenção fotográfica inserida na pesquisa intervenção como uma estratégia metodológica que tensiona as linhas de visibilidade e os modos de ver, provocando reflexões e intervenções.

Entende-se que o desenho da pesquisa intervenção, o acompanhamento do processo e as análises produzidas no percurso de uma pesquisa estão ligados à uma prática de si do sujeito pesquisador. Neste modo de pesquisar, não há produção dissociada de exercícios reflexivos deste sujeito sobre si mesmo, o que configura a pesquisa como um exercício ético. Logo, o processo de pesquisa, com suas regularidades e mudanças, pode ser tomado como uma prática reflexiva, convocando incessantes questionamentos sobre as condições de sujeição de si e dos outros e sobre as possibilidades de liberdade nestas condições.

A ética afirma a possibilidade de reflexão sobre o exercício de liberdade nas relações de poder, pois "a liberdade é a condição ontológica ${ }^{1}$ da ética [no sentido de fundamento real, substrato]. Mas a ética é a forma reflexiva que adota a liberdade" (FOUCAULT, 1996, p. 98, tradução nossa). Como aponta Foucault (1996, p. 98, tradução nossa) "o que é a ética se não a prática da liberdade, a prática reflexiva da liberdade?". São práticas que passam por reflexão e pensamento sobre si e sobre o mundo, e sobre este "si" no mundo. Nesse sentido, apresentam potencial de transformar as relações e os próprios sujeitos.

A noção de prática de si está ligada à ética do cuidado de si na Antiguidade, designando exercícios, operações e formas de relação do sujeito consigo mesmo. Estas são realizadas com o objetivo de preparar-se para os acontecimentos da vida e transformar-se.

Tomando a ética como problematização da liberdade, o exercício ético da pesquisa consiste em interrogar, provocar e tensionar as relações de poder e as condições de sujeição na busca dos espaços de criação, de produção de diferenças e de reflexões possíveis no campo de pesquisa. No contexto da pesquisa intervenção, este exercício pode ser entendido como análise de implicação, que é um exercício que não está localizado em um momento específico da pesquisa ou em um determinado elemento da metodologia, mas como condição de possibilidade de constituição de si do sujeito pesquisador e do campo de pesquisa, concomitantemente. Para Lourau (2004, p. 190):

A implicação é um nó de relações; não é "boa" (uso voluntarista) nem "má" (uso jurídico-policialesco). A sobreimplicação, por sua vez, é a ideologia normativa do sobretrabalho, gestora da necessidade do "implicar-se". O útil ou necessário para a ética, a pesquisa e a ética da pesquisa 
não é a implicação - sempre presente em nossas adesões e rechaços, referências e não referências, participações e não-participações, sobremotivações e desmotivações, investimentos e desinvestimentos libidinais... -, mas a análise dessa implicação.

Nesta discussão, a análise de implicação não é uma parte da pesquisa, mas sim, condição de existência da pesquisa e constitui todo o processo. A própria reflexão teórica também é um exercício de análise de implicação, pois indica os modos como os conceitos são agenciados em função da trajetória e da constituição do sujeito-pesquisador-escritor, que acontece na experiência da pesquisa, e não de modo a priori. A escrita, então, também é processo, exercício e prática de si que pode provocar transformações.

Para Foucault (2006a, p. 146), "nenhuma técnica, nenhuma habilidade profissional pode ser adquirida sem exercício; não se pode mais aprender a arte de viver, a technê tou biou, sem uma askêsis que deve ser compreendida como um treino de si por si mesmo [...]". Assim, o processo de pesquisa implica as práticas conceitos e análises articulados na arte e viver.

A ascese, na antiguidade, teve como objetivo "[...] chegar à formação de uma certa relação de si para consigo que fosse plena, acabada, completa, autossuficiente e suscetível de produzir a transfiguração de si que consiste na felicidade que se tem consigo mesmo" (FOUCAULT, 2006b, p. 386). É deste lugar de implicação, de prática de si e de reconhecimento das condições de sujeição que a experiência do pesquisar torna-se possível e que a trajetória da pesquisa se desenvolve.

Pode-se entender as considerações que Foucault refere sobre os hypomnémata como elementos importantes para o processo de escrita de uma pesquisa. Nesta prática comum entre os antigos,

\begin{abstract}
A escrita como exercício pessoal feito por si e para si é uma arte da verdade díspar; ou, mais precisamente, uma maneira racional de combinar a autoridade tradicional da coisa já dita com a singularidade da verdade que nela se afirma e a particularidade das circunstâncias que determinam seu uso (FOUCAULT, 2006a, p. 151).
\end{abstract}

Esta arte da verdade é um importante recurso na produção de diferença que pode ser efeito deste exercício de escrita. Os argumentos de autoridade, os referenciais teóricos e as problematizações conceituais clássicas e consagradas, pouco dizem, comunicam ou transmitem sobre as singularidades do processo e sobre a experiência se não estiverem inseridos em um exercício de reflexão e de apropriação pelo sujeito-pesquisador-escritor. Cabe ressaltar que o processo singular da escrita, essa ruptura que se dá no encontro entre as coisas já ditas e a configuração que vai ganhando forma na experiência do sujeito-pesquisador-escritor insere-se nas condições de possibilidade que circunscrevem e contextualizam este processo (condições teóricas, linguísticas, práticas, políticas, culturais, históricas, entre outras). 
A escrita é um dos elementos dessa ascese do sujeito-pesquisador-escritor, da constituição dessa relação de si para consigo. Mas qual é a tática, qual é o instrumento desta ascese? Podemos pensar que a paraskeué está para a ascese assim como a metodologia está para a experiência da pesquisa. A paraskeué é uma das táticas da ascese, uma de suas estratégias. Assim, podemos entender a metodologia como uma paraskeué, um equipamento.

[...] a paraskeué é o que se poderia chamar uma preparação ao mesmo tempo aberta e finalizada do indivíduo para os acontecimentos da vida. Quero com isto dizer que se trata, na ascese, de preparar o indivíduo para o futuro, um futuro que é constituído de acontecimentos imprevistos, acontecimentos cuja natureza em geral talvez conheçamos, os quais porém não podemos saber quando se produzirão nem mesmo se se produzirão. Trata-se pois, na ascese, de encontrar uma preparação, uma paraskeué capaz de ajustar-se ao que possa se produzir, e a isto somente, no momento exato em que se produzir, caso venha a produzirse (FOUCAULT, 2006b, p. 387, grifo do autor).

Esta posição afirma a existência das determinações, conceitos e lógicas, e que estas não são dadas a priori, antes da experiência, antes do encontro do sujeito com o campo de práticas. Logo, a paraskeué deste sujeito-pesquisador-escritor, seu equipamento e sua preparação para o imprevisível são configurados por uma posição ética, pela abertura para os encontros e as multiplicidades.

O equipamento da paraskeué é constituído pelos lógoi (discursos), os quais não se reduzem a um conjunto de conceitos e princípios que sejam verdadeiros (FOUCAULT, 2006b). São discursos e proposições que foram adquiridos em sua materialidade (frases efetivamente ouvidas e lidas pelo sujeito, e escritas e rememoradas por ele, por exemplo) e são "fundadas na razão, isto é, ao mesmo tempo em que são razoáveis, são verdadeiras e constituem princípios aceitáveis de comportamento" (FOUCAULT, 2006b, p. 390). Segue-se disso que "a paraskeué é o elemento de transformação do logos em êthos" (FOUCAULT, 2006b, p. 394, grifo do autor) e a áskesis "é o que permite que o dizer-verdadeiro [...] constitua-se como maneira de ser do sujeito" (FOUCAULT, 2006b, p. 395).

Deste modo, são os pressupostos e estratégias metodológicas e a metodologia, enquanto tática, que dão as condições para transformar os discursos que compõem os jogos de verdade em um exercício ético, em uma prática reflexiva. A pesquisa-intervenção pode permitir este investimento em função de seus pressupostos, posições e características.

Destaca-se ainda que os jogos de verdade produzidos no percurso da pesquisa são configurados menos por uma "retórica" do que por uma parrhesía. Para Foucault, a retórica pode ser definida como "uma técnica cujos procedimentos não têm evidentemente por finalidade estabelecer uma verdade, mas como uma 
arte de persuadir aqueles a quem nos endereçamos, pretendendo convencê-los quer de uma verdade quer de uma mentira [...]" (FOUCAULT, 2006b, p. 461). Persuasão e convencimento não são o objetivo deste tipo de escrita e de reflexões.

Trata-se, então, não de uma retórica, mas do dizer verdadeiro, do falar francamente, pois "na parrhesía só pode haver verdade. Onde não houver verdade não há franco-falar” (FOUCAULT, 2006b, p. 462, grifo do autor). Logo, o exercício ético do sujeito-pesquisador-escritor é configurado por uma parrhesía, por um dizer verdadeiro que não pretende subjugar os outros ou torná-los dependentes, mas é comandado pela generosidade como obrigação moral (FOUCAULT, 2006b).

Nesse sentido, o que define essencialmente as regras da parrhesía é o kairós, a ocasião, ocasião que é exatamente a situação dos indivíduos em relação uns aos outros e o momento escolhido para dizer a verdade. É precisamente em função daquele a quem nos endereçamos e do momento em que a ele nos endereçamos que a parrhesía deve modalizar não o conteúdo do discurso verdadeiro, mas a forma com que este discurso é sustentado (FOUCAULT, 2006b, p. 464, grifo do autor).

Temos assim, a partir deste desenvolvimento, a pesquisa como uma ascese, como prática de si do sujeito pesquisador que tem a metodologia da pesquisa-intervenção e seus pressupostos como tática e como equipamento (paraskeué). Esse equipamento que torna o sujeito disponível para a experiência a partir de uma posição ética não é configurado por uma performance discursiva, por uma retórica, mas por um modo de falar francamente que tem um compromisso com a verdade. Esses elementos orientam um desenho metodológico que se desdobra nas práticas propostas pela pesquisa intervenção e pela intervenção fotográfica.

A Pesquisa Intervenção amplia as bases teórico-metodológicas das pesquisas participativas, enquanto proposta de transformação da realidade sócio-política, pressupondo uma intervenção micropolítica na experiência social (AGUIAR; ROCHA, 2003). Essa forma de pesquisar pressupõe constantes reformulações que vão ocorrendo na construção do problema e do processo, juntamente com os sujeitos que constituem o campo de intervenção, na qual pesquisador e campo vão se transformando mutuamente. É a experiência e o encontro que constituem o processo.

Entreosaspectos centrais quevêmnorteandoodesenvolvimento da pesquisa-intervenção, destacamos os seguintes: mudança de parâmetros de investigação no que tange à neutralidade e à objetividade do pesquisador, acentuando-se o vínculo entre gênese teórica e social, assim como a produção concomitante do sujeito e do objeto, questionamento dos especialismos instituídos, ampliando as análises do nível psicológico ao microssocial - deslocamento estratégico do lugar que historicamente foi destinado ao psicólogo, ênfase na análise da implicação, acentuando-se que, para além dos vínculos 
afetivos, profissionais ou políticos, a análise se realiza com as instituições que atravessam o processo de formação (AGUIAR; ROCHA, 2003, p. 71).

Nesse sentido, estas estratégias permitem que o processo de pesquisar acompanhe os caminhos e desvios que vão sendo produzidos nos encontros entre os sujeitos. Entre as estratégias de registro de experiência e de análise, destaca-se a análise de implicação, o diário de campo e a ênfase no processo, que são importantes em toda a trajetória da pesquisa. Estas podem constituir formas de potencializar o exercício de si do pesquisador e seus efeitos. Os registros e relatos no diário de campo permitem análises sempre inacabadas, pois é possível rever a trajetória da pesquisa e produzir sentidos outros ao que foi vivido, dando condições para a análise de implicação.

As análises, nesta orientação metodológica, são produzidas a partir dos analisadores que emergirem ao longo do processo da pesquisa e que podem dar visibilidade e provocar os dispositivos que configuram as relações de poder nas quais se produzem. Dessa forma, a questão que se coloca como importante na pesquisa é analisar como os dispositivos podem ser visibilizados ou provocados neste espaço, através da construção dos analisadores, que podem colocar tais dispositivos e seus efeitos em análise.

Dispositivo e analisador são termos que se ligam e se relacionam, mas são distintos entre si. Para Baremblitt (1998, p. 71), "um analisador não é apenas um fenômeno cuja função específica é exprimir, manifestar, declarar, evidenciar, denunciar. Ele mesmo contém os elementos para se autoentender, ou seja, para começar o processo de seu próprio esclarecimento". Um analisador visibiliza relações, dá a ver diferentes práticas e agenciamentos e potencializa, ao mesmo tempo, o processo para entender e esclarecer o que o próprio analisador faz em determinado campo, o que movimenta, o que permite, o que provoca.

Os dispositivos ${ }^{2}$ presentes no campo de pesquisa indicam as condições históricas e as relações heterogêneas que fazem-nas funcionar em determinado sentido, pois "pertencemos a dispositivos e neles agimos" (DELEUZE, 1996, p. 92). Os analisadores podem mostrar os efeitos de dispositivo, os modos como se atualiza na especificidade do contexto da pesquisa e mostrar suas fragilidades e possibilidades de ruptura. Este processo produz relações e análises singulares, não serializadas, as quais permitem a emergência de alguns analisadores, em função dos movimentos e dos encontros, das problematizações e das reflexões. A escolha de analisadores é importante para que seja possível potencializar diversos processos de mudança e de rupturas neste campo de relações de poder.

Esta mútua implicação das noções apresentadas provoca uma relação de coexistência entre ambas. Aquilo que emerge como analisador, que dá a ver a multiplicidade de relações em um campo de práticas, que manifesta e evidencia lógicas e funcionamentos só pode fazê-lo inserido em processos de subjetivação, 
imerso em um campo de visibilidades, de dizibilidades e de relações de poder, que indicam os dispositivos como conteúdo histórico, heterogêneo e como máquina de fazer ver e de fazer falar ali agenciada.

Ressaltamos a perspectiva da intervenção fotográfica (TITTONI, 2009), que, inserida no contexto da pesquisa-intervenção, busca problematizar/tensionar os modos de ver, de modo a provocar as éticas de ver e ampliar as possibilidades de olhar e as condições de visibilidade nos processos sociais e históricos. Em uma sociedade marcada pelas imagens, onde a imagem funciona como estratégia de comunicação que convoca o olhar, a intervenção fotográfica constitui-se como possibilidade de tensionar os efeitos de poder que produzem linhas de visibilidade e invisibilidade, que configuram modos e processos de subjetivação.

A intervenção fotográfica pode ser tomada como estratégia metodológica e como equipamento, como paraskeué, potencializando a pesquisa como ascese, como exercício ético. A produção de fotografias e a consequente reflexão sobre as imagens constitui um exercício que pode ser tomado como equipamento da ascese. Este exercício é materializado na câmera fotográfica e no aparelho, que produz imagens desde um ponto de vista que diz respeito a um modo de ver singular.

Imagens em movimento (que constituem um filme) convocam um olhar dinâmico e flutuante, pois não cessam de se alternar, estabelecendo uma relação de "passagem" com o tempo. Por outro lado, a fotografia convoca um outro tipo de olhar. A fotografia enfatiza um ponto de vista, um modo de ver, e produz uma necessidade de "sustentação" do olhar. Neste sentido, inserida neste tempo que corre incessantemente, a fotografia convida a tomar um ponto de vista, sustentar um olhar e "suportar" um tempo tanto para fotografar, quanto para ver as fotografias e refletir sobre elas.

O que é atual é sempre um presente. Mas, justamente, o presente muda ou passa. Pode-se sempre dizer que ele se torna passado quando já não é, quando um novo presente o substitui. Mas isso não quer dizer nada. Certamente é preciso que ele passe, para que o novo presente chegue, que passe ao mesmo tempo que é presente, no momento em que o é. É preciso, portanto, que a imagem seja presente e passada, ainda presente e já passada, a um só tempo, ao mesmo tempo. Se não fosse já passada ao mesmo tempo que presente, jamais o presente passaria. O passado não sucede ao presente que ele não é mais, ele coexiste com o presente que foi. O presente é a imagem atual, e seu passado contemporâneo é a imagem virtual, a imagem especular (DELEUZE, 2005a, p. 99, grifo do autor).

A própria fotografia pode ser tomada como instante, a fotografia como um tempo passado e presente, pois o presente está em constante atualização. Nesse sentido, possibilitar a realização de fotografias no contexto da pesquisa, convocar a sustentação de um olhar sobre a imagem e a consequente reflexão sobre este exercício pode provocar rupturas e tensionamentos na dinâmica das relações. A fotografia não passa, ou melhor, ela se torna passado, mas há sempre uma "pre- 
sença" da imagem que se atualiza no presente. Ela contém um instante, um tempo, dá a ver um ponto de vista, uma perspectiva e para que se produzam sentidos sobre a imagem, há que se sustentar um olhar. E sustentar um olhar é ter uma posição reflexiva. Olhar, contemplar e refletir configura uma ética do ver.

De acordo com Susan Sontag, as fotografias nos ensinam um novo código visual, modificando e ampliando nossas ideias acerca do que vale a pena olhar. Nesse sentido, as fotografias "constituem uma gramática e, mais importante ainda, uma ética do ver" (SONTAG, 2004, p. 13). A sociedade contemporânea é marcada pelas imagens, um mundo de imagens que convoca o olhar, que agencia possibilidades de olhar sob certas condições de visibilidade, inseridas nos processos sociais e históricos. Esses agenciamentos provocados pelas imagens constituem uma ética do ver, um modo de ver o mundo por meio de fotografias e imagens, que já não são mais apreendidas como cópia da realidade (como nos tempos do surgimento da fotografia na modernidade e no seu uso comum até os dias de hoje), mas como uma produção da própria realidade. De acordo com Susan Sontag (2004, p. 196, grifo do autor):

[...] a força das imagens fotográficas provém de serem elas realidades materiais por si mesmas, depósitos fartamente informativos deixados no rastro do que quer que as tenha emitido, meios poderosos de tomar o lugar da realidade ao transformar a realidade numa sombra. As imagens são mais reais do que qualquer um poderia supor [pois elas produzem realidades].

Para Roland Barthes (1984, p. 15) “a Fotografia sempre traz consigo seu referente, ambos atingidos pela mesma imobilidade amorosa ou fúnebre, no âmago do mundo em movimento: estão colados um ao outro [...]". Diferentemente do autor, na perspectiva deste estudo, a imagem fotográfica necessita um referente, mas não está "colada" a ele, trazendo potência para sua utilização/produção/reflexão como forma de intervenção nos modos de ver. Essa tensão quebra com a ideia construída ao longo da modernidade de que uma imagem seria uma réplica do mundo real, uma cópia fiel e indiscutível da realidade.

Tomar a imagem não apenas como representação de uma unidade, mas como criação e alteridade, transforma a concepção de cópia em uma produção, na medida em que a imagem pode evocar sentidos outros que não estão colados ao seu referente. Ainda, nesse sentido, pensar a imagem como produção e como diferença opõe-se a concepção moderna de que há uma realidade a ser captada e uma essência a ser revelada muito associada às produções fotográficas.

Além de a fotografia constituir, por meio de seu aparato tecnológico, “um modo de atestar a experiência" (SONTAG, 2004, p. 20), segundo a autora, produzir fotografias também é uma forma de recusar a experiência, convertendo-a em uma imagem, um souvenir. Nesse sentido, a autora afirma que o ato de fotografar "dá forma" a experiência, circunscrevendo-a. No entanto, ao mesmo tempo, pode-se pensar que fotografar "deforma" a experiência daquilo que está 
sendo fotografado, pois congela em um espaço (neste caso o papel) um processo contínuo, que de outra forma nunca seria visto dessa perspectiva e desse modo. Por outro lado, este exercício dá forma a experiência de fotografar, ao ato de focalizar algo através de lentes que registram determinado objeto, pessoa, lugar, momento, entre outras possibilidades.

Ainda, segundo a autora, fotografar é um ato de não intervenção, pois "a pessoa que interfere não pode registrar; a pessoa que registra não pode interferir" (SONTAG, 2004, p. 22). Entretanto, analisando o "fotografar" (como ação) a partir da perspectiva da intervenção fotográfica (TITTONI, 2009), pode-se pensar que há uma intervenção não sobre a coisa fotografada, mas sobre o ato de fotografar, de exercitar um olhar fotográfico e de provocar outros modos de ver. A intervenção fotográfica, inserida no contexto da pesquisa-intervenção, busca tensionar, problematizar e provocar os modos de ver e as éticas do ver de modo a intervir nas linhas de visibilidade/invisibilidade nos processos sociais e históricos, convocando produções e reflexões.

A partir de uma perspectiva foucaultiana, podemos pensar que as imagens são produzidas nas relações de poder, que configuram linhas de visibilidade e invisibilidade, e são os jogos de verdade que legitimam discursos de verdade nos diferentes contextos. Tal concepção está de acordo com a discussão acerca da fotografia como produção dos modos de ver e de uma ética do ver, e não como uma reprodução idêntica do mundo. Sobre as visibilidades, Deleuze (2005b, p. 66) ressalta que:

[...] as visibilidades, por sua vez, por mais que se esforcem para não se ocultarem, não são imediatamente vistas nem visíveis. Elas são até mesmo invisíveis enquanto permanecermos nos objetos, nas coisas ou nas qualidades sensíveis, sem nos alçarmos até a condição que as abre. E se as coisas se fecham de novo, as visibilidades se esfumam ou se confundem, a tal ponto que as "evidências" se tornam incompreensíveis a uma outra época [...] A condição à qual a visibilidade se refere não é, entretanto, a maneira de ver de um sujeito: o próprio sujeito que vê é um lugar na visibilidade, uma função derivada da visibilidade [...].

Nesse sentido, a visibilidade, se tomada apenas como aquilo que é visível pelo sentido da visão (olho humano), pela visão imediata dos objetos, pode se tornar invisível, ocultando a perspectiva de que há uma produção de visibilidade inserida nas condições de possibilidade de uma época, nas quais o sujeito também é produzido como um lugar nesta visibilidade. Cada um que olha, olha com olhos múltiplos, atravessados por diversos discursos que constituem possibilidades de ver que nunca serão as mesmas. Portanto, estas possibilidades são sempre atualizadas no presente de quem olha.

As imagens supõem um passado e um presente que não cessa de se atualizar, e de passar, convocando uma ética do ver que não é da ordem da individualidade. Isso sugere não tomar as fotografias produzidas na pesquisa como "o" campo 
de visibilidade, especificamente, como se o visível se reduzisse a imagem. A visibilidade produz-se nas condições históricas, políticas, culturais, institucionais, sociais, nas quais os sujeitos também são uma produção e um lugar neste visível.

A mesma problematização da visibilidade pode ser referenciada ao entendimento dos enunciados e das dizibilidades, pois, para Deleuze "eles [os enunciados] nunca estão ocultos, e no entanto não são diretamente legíveis, sequer dizíveis. Poder-se-ia crer que os enunciados frequentemente estão ocultos, sendo objeto de um disfarce, de uma repressão ou menos de um recalque" (DELEUZE, 2005b, p. 62), hipótese que Foucault (2009) desconstrói na discussão sobre a sexualidade no livro $A$ vontade de saber. ${ }^{3}$ Dessa forma, destaca-se que:

Em suma, se não nos alçamos até suas condições extrativas, o enunciado continua oculto; desde que tenhamos atingido as condições, ao contrário, ele está visível e diz tudo. [...] Que tudo seja sempre dito, em cada época, talvez seja esse o maior princípio histórico de Foucault: atrás da cortina nada há para se ver, mas seria ainda mais importante, a cada vez, descrever a cortina ou o pedestal, pois nada há atrás ou embaixo (DELEUZE, 2005b, p. 63).

Em síntese, o visível e o dizível não são reduzidos ao olhar e a fala, pois isso obscurece a complexidade destas produções. Além disso, as visibilidades e as dizibilidades não são imediatamente perceptíveis nem óbvias, mesmo que explícitas, e ao mesmo tempo não há nada por trás ou ao lado, pois tudo é dado a ver e a enunciar. O que é importante são as condições de possibilidade dos enunciados e das visibilidades, as quais são muito mais do que o dizer e o ver, pois se desenvolvem nas relações de poder que abrangem a história, a economia, a política, o governo, as instituições, a cultura, entre tantos outros elementos.

Este posicionamento de entender o processo de pesquisar como uma prática de si do sujeito-pesquisador-escritor, uma ascese, que pode ter como equipamentos, como paraskeué, a pesquisa intervenção e a intervenção fotográfica, constitui uma estratégia potente de reflexão ética construída na prática e como experiência. Tensionando, principalmente, as linhas de visibilidade e de invisibilidade em um processo de pesquisa, tais equipamentos produzem efeitos interessantes e materialidades que provocam e convocam reflexões.

\section{Notas}

${ }^{1}$ Esta condição ontológica não pode ser entendida de modo objetificado, reificado: só existe ética quando há liberdade, só há liberdade quando há resistência, escolhas e deslocamentos dos sujeitos. Logo, a liberdade é um pressuposto a priori da ética que não pode ser demonstrado, mas reivindicado como uma "condição de possibilidade" da ética.

${ }^{2}$ Segundo Deleuze (1996, p. 92-93), “À novidade de um dispositivo em relação aos que o precedem chamamos actualidade do dispositivo, a nossa actualidade. O novo é o actual. $\mathrm{O}$ actual não é o que somos, mas aquilo em que nos vamos tornando, aquilo que somos em devir, quer dizer, o Outro, o nosso devir-outro. É necessário distinguir, em todo o dispositivo, o que somos (o que não seremos mais), e aquilo que somos em devir: a parte da história e a parte do actual".

${ }^{3}$ Sobre a hipótese repressiva ler Foucault (2009). 


\section{REFERÊNCIAS}

AGUIAR, K. F. de; ROCHA, M. L. da. Pesquisa-intervenção e a produção de novas análises. Psicologia Ciência e Profissão, [S.1.], 2003, v. 23, n. 4, p. 64-73.

BAREMBLITT, G. F. Compêndio de Análise Institucional e outras correntes: teoria e prática. 4. ed. Rio de Janeiro: Record - Rosa dos Tempos, 1998.

BARTHES, R. A câmara clara: nota sobre a fotografia. 3. ed. Rio de Janeiro: Nova Fronteira, 1984.

DELEUZE, G. O que é um dispositivo? In: . O mistério de Ariana: cinco textos e uma entrevista de Gilles Deleuze. Lisboa: Passagens, 1996. p. 83-96.

DELEUZE, G. A imagem-tempo: cinema 2. São Paulo: Brasiliense, 2005a.

DELEUZE, G. Foucault. São Paulo: Brasiliense, 2005b.

FOUCAULT, M. La ética del cuidado de uno mismo como práctica de la libertad. In: . Hermenéutica del sujeto. La Plata: Altamira, 1996. p. 93-125.

FOUCAULT, M. A escrita de si. In: . Ética, Sexualidade, Política. 2. ed. Rio de Janeiro: Forense Universitária, 2006a. Coleção Ditos \& Escritos, v. 5, p. 144-162.

FOUCAULT, M. A hermenêutica do sujeito: curso dado no Collège de France (1981-1982). 2. ed. São Paulo: Martins Fontes, 2006b.

FOUCAULT, M. História da sexualidade: a vontade de saber. 19. ed. Rio de Janeiro: Graal, 2009. v. 1.

LOURAU, R. René Lourau: analista institucional em tempo integral. São Paulo: Hucitec, 2004.

SONTAG, S. Sobre fotografia. São Paulo: Companhia das Letras, 2004.

TITTONI, J. (Org.). Psicologia e fotografia: experiências em intervenções fotográficas. Porto Alegre: Dom Quixote, 2009.

Recebido em: 03 de maio de 2012 Aceito em: 11 de setembro de 2013 
